\title{
Unidades léxicas tabus nos dicionários on-line Michaelis, Aulete e Priberam
}

\author{
Taboo lexical units in the online dictionaries \\ Michaelis, Aulete, and Priberam
}

\author{
Vivian Orsi \\ Universidade Estadual Paulista Júlio de Mesquita Filho, São Paulo, São Paulo, Brasil
}

\begin{abstract}
Resumo: O léxico de uma língua permite que nele se entreveja o modo como a comunidade percebe o mundo que a circunda, em seus diferentes aspectos. Dentro de cada item lexical são postas e expostas todas as informações. Assim, por meio do seu estudo podemos ter uma ideia de preconcepções e tabus que permeiam a sociedade. Neste artigo procuramos compreender as unidades tabus e sua importância na língua, elegendo como objeto de estudo a definição e a aposição de marcas de uso a alguns itens lexicais que têm uma ou mais acepções consideradas ofensivas, e por isso tabus, dentro de alguns verbetes, nos dicionários disponíveis on-line Aulete, Michaelis e Priberam. Tendo como respaldo as teorias das duas grandes ciências em que se enquadra esta pesquisa, Lexicologia e Lexicografia, com alicerce em Béjoint (2000), Borba (2003), Bugueño Miranda e Borba (2019), Henriques (2011) e Welker (2004), esperamos colaborar para a discussão sobre a temática das rubricas em obras de consulta e a pouca atenção que recebem de lexicógrafos.
\end{abstract}

Palavras-chave: Léxico Tabu; Marcas de uso; Dicionários

\begin{abstract}
The lexicon of a language allows to see how the community perceives the world around it, in its different aspects. Within each lexical item, all information is posted and exposed. Thus, through its study, we can have an idea of preconceptions and taboos that are present in society. In this article, we try to understand the taboo units and their importance in the language, choosing to study the definition and the labels that come with to some lexical items that have one or more meanings considered offensive, and therefore taboos, within some entries, in the dictionaries available online Aulete, Michaelis and Priberam. Based on the theories of the two great sciences in which this research is included, Lexicology and Lexicography, we hope to bring some contribution to the discussion on the labels in dictionaries and the little attention they receive from lexicographers.
\end{abstract}

Keywords: Taboo Lexicon; Labels; Dictionaries 


\section{Introdução}

O léxico compreende todas as criações verbais de uma língua, incluindo “(...) desde as preposições, conjunções ou interjeições, até os neologismos, regionalismos, passando pelas terminologias, pelas gírias, expressões idiomáticas e palavrões” (HENRIQUES, 2011, p. 13). Ademais, ele é um conjunto aberto, em constante movimento de expansão, retração e adaptação. Neste trabalho escolhemos o léxico da linguagem proibida como nosso objeto, especificamente, as lexias que podem ser consideradas tabus, aquelas consideradas estigmatizadas socialmente, escatológicas (referentes aos excrementos), etnônimos injuriosos (que se referem a certos grupos e serão definidos adiante), o ato e os órgãos sexuais, conforme Guérios (1956), Kasama (2015) e Orsi e Bueno (2014), com foco no modo com que são rubricadas nas obras on-line Michaelis, Aulete e Priberam.

Esta pesquisa visa reforçar, em linhas gerais, que opiniões, posicionamentos e valores são imputados socialmente às palavras. No âmbito dos tabus, a linguagem proibida indica uma visão depreciativa, que censura socialmente as suas unidades lexicais.

Vejamos, então, a motivação para serem consideradas tabus e como se manifestam na língua e disseminam preconceitos.

\section{Tabus linguísticos}

Conforme Orsi (2011, p. 3), “o tabu linguístico é decorrente das sanções, restrições e escrúpulos sociais; atua na não permissão ou na interdição de se pronunciar ou dizer certos itens lexicais". Disso fica claro que o léxico carrega em si princípios e morais que lhe são atribuídos pela sociedade em que é empregado, e que pode sofrer mudanças, conforme elas ocorram.

$\mathrm{Na}$ linguagem proibida, em que se inserem as lexias chulas e depreciativas, há unidades léxicas condenadas pela sociedade e que, por esse motivo, são consideradas tabus linguísticos.

Há um desvelado temor por alguns itens. Nessa esteira, o temor à morte tabuiza 0 verbo morrer e produz sinônimos livres de tabus, como as expressões idiomáticas 'bater 
as botas', 'esticar as canelas' ou 'abotoar o paletó'. Ainda, ao invés de se referir à lexia 'diabo', usa-se o 'malvado' ou o 'chifrudo'.

Vemos que os tabus podem ser substituídos por eufemismos - que têm a capacidade de neutralizar uma unidade tabuística (MORALES, 2006) ou por disfemismos, os quais, para Guérios (1956) são expressões agravantes.

\section{Tabus nos dicionários}

No âmbito deste trabalho fizemos a seleção de alguns itens que possuem dentro dos verbetes uma de suas acepções considerada tabu e, portanto, negativa, e que os dicionários, carecendo de imparcialidade, reproduzem.

Para embasar nossas análises, é mister fazer algumas considerações sobre a Lexicografia, entendida, resumidamente, como a ciência que tem como objetivo a elaboração ou compilação de obras de consulta como dicionários e vocabulários e seu estudo teórico.

Um dicionário ideal seria aquele baseado nos princípios teóricos da Lexicografia e imparcial na apresentação do seu conteúdo.

Assim, na sua microestrutura - vale dizer, dentro do conjunto de informações sobre o signo-lema (BUGUEÑO MIRANDA; BORBA, 2019) -, em especial no comentário semântico, deve haver o apagamento do lexicógrafo. Isto pois, o dicionário representa para uma sociedade o meio transmissor de informação, que deveria ser objetiva e reconhecida socialmente como uma verdade. Esse seria o modelo exemplar de dicionário.

Dentro dos verbetes, é aconselhável que dicionários tragam informações adicionais sobre o uso, por exemplo. A marca de uso, ou rubrica, para Fajardo (19961997, p.31, tradução nossa):

é o recurso ou procedimento que se utiliza no dicionário para indicar a
particularidade do uso, de caráter não regular, que distingue certos itens
lexicais. (...) A rubrica tem uma função fundamental: caracterizar um
elemento lexical marcando suas restrições e condições de uso (...). As marcas
de uso são as informações específicas sobre os diversos tipos de 
particularidades que restringem ou vinculam o uso de unidades lexicais (FAJARDO, 1996-1997, p. 31, tradução nossa). ${ }^{1}$

Dentro desses dados, podemos destacar o que Hausmann (1977 apud WELKER, 2004, p. 131) define como informação diaevaluativa, um tipo de marca de uso que diz respeito à atitude do falante, mais precisamente, etiquetas como 'depreciativo', 'pejorativo', 'vulgar', 'eufemístico' e 'irônico'. Essas etiquetas são marcas de natureza pragmática, mas que também dão informação sobre a valoração social que faz a comunidade, pois seus usos são carregados de intencionalidade, como a de ofender.

No entanto, o que se percebe nos verbetes a seguir apresentados é um descuido ou efetiva tomada de posição em dicionários que aparentam neutralidade. A marcação dos usos de unidades léxicas é um campo em que se verifica com frequência esse posicionamento ou falta de precisão ou aviso ao consulente do dicionário.

Sobre nossa metodologia, como nosso objetivo é investigar a marcação de alguns verbetes específicos, este trabalho é descritivo com caráter qualitativo. Para tanto, precisamos que as três obras consultadas como fonte são os dicionários Michaelis, o iDicionário Aulete e Priberam, disponíveis gratuitamente na internet, foram escolhidas por estarem entre as mais populares no Brasil (FRANKENBERG-GARCIA, 2017).

Primeiramente, procedemos à seleção dos lemas. Os itens sobre os que nos debruçamos são 'sogra', 'madrasta', 'cigano', 'judeu', 'paulista', 'mijo', 'trepada' e 'comida'. Após, na segunda fase, atentamos ao modo como estão registrados e qual a marcação (se houver). Por fim, trazemos o verbete, mas ressaltamos, de cada um, a acepção nosso objeto de exame e sempre relativa a substantivos.

Vejamos a lexia 'sogra', que pode ser tomada como tabu ao ser associada à pessoa má, invasiva, que interfere na vida do casal. Muitos evitam a referência à sogra, usando a expressão "a mãe de tal" (nome da mulher) ou "dona tal" (nome da sogra), ou ainda bruxa e jararaca. Já para sogro não há tabu.

Porém, apesar de existir essa valoração pejorativa insultuosa e de haver grande número de piadas sobre "sogras" e sua presença como pessoa perversa ser recorrente em

\footnotetext{
1 "es el recurso o procedimiento que se utiliza en el diccionario para señalar la particularidad de uso, de carácter no regular, que distingue a determinados elementos léxicos. (...). La marcación cumple una función fundamental: caracterizar a un elemento léxico señalando sus restricciones y condiciones de uso (...). Las marcas son las informaciones concretas sobre los muy diversos tipos de particularidades que restringen o condicionan el uso de las unidades léxicas.” (FAJARDO, 1996-1997, p. 31).
} 
outros textos humorísticos, consoante Silva de Melo (2014), curiosamente não há no dicionário Michaelis um verbete destinado a essa lexia.

Aulete e Priberam propõem um verbete, que, no entanto, carece de referência a esse aspecto negativo de 'sogra'.

\begin{tabular}{|l|l|}
\multicolumn{1}{l}{ Figura 1 - sogra - Aulete } \\
\hline sogra \\
(so.gra) \\
sf. \\
1. A mãe de um dos cônjuges em relação ao outro \\
[F.: Do lat. vulg. socra, de socrus, us] \\
\end{tabular}

Fonte: dicionário Aulete

Figura 2 - sogra - Priberam

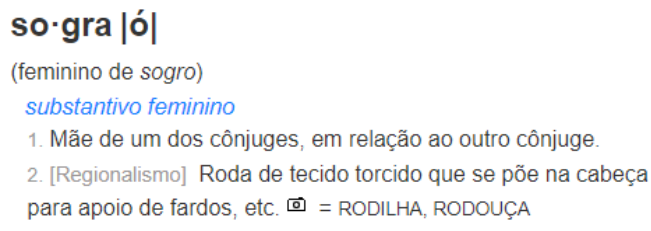

Fonte: dicionário Priberam

Para o item 'madrasta', os dicionários consultados registram acepções que giram em torno de pessoa pouco carinhosa e insensível.

No dicionário Michaelis, na acepção de número 2 consta a rubrica 'figurado':

Figura 3 - madrasta - Michaelis

\begin{tabular}{|l|}
\hline madrasta \\
ma.dras.ta \\
sf \\
1 Mulher casada em relaçăo aos filhos que seu marido teve de casamentos anteriores. \\
2 Fi̊ Mulher má, incapaz de revelar gestos de ternura. \\
\hline
\end{tabular}

Fonte: dicionário Michaelis

No dicionário Aulete, na acepção de número 2, também há a carga pejorativa, marcada com a rubrica figurado. 
Figura 4 - madrasta - Aulete

madrasta
(ma. dras.ta)
sf.
1. Mulher casada com o pai de uma pessoa, sem ser sua mãe
2. Fig. Mãe ou mulher má, pouco carinhosa, insensivel
$\quad$ [F.: Do lat.pop. matrasta 'mulher do pai \#\#\#\#]

Fonte: dicionário Aulete

Já no Priberam tem-se:

Figura 5 - madrasta - Priberam

ma·dras·ta
(latim vulgar matrastra, do latim mater, -tris, mãe)
substantivo feminino
1. Esposa ou companheira do pai, ou da mãe em casais do mesmo
sexo, em relação aos filhos por eles tidos em relacionamento
anterior.
2. [Depreciativo] Mãe que não cuida bem dos filhos.
3. [Depreciativo] Mulher má.

Fonte: dicionário Priberam

Vemos que entre Aulete e Michaelis há consenso em usar a rubrica figurado, definido por ambos como um sentido que se vale da metáfora ou de outra figura de linguagem. Ou seja, nada se explica sobre esse uso tabu e de carga semântica negativa. No Priberam, com a marcação mais adequada, em nossa opinião, é indicado o uso depreciativo tanto na acepção 2 , de mulher pouco cuidadosa com filhos, quanto na 3 , ligada à maldade. Para depreciativo, o referido dicionário pontua que é algo desdenhoso e humilhante.

Já ao fazermos uma busca por nomes de grupo étnicos, pode acontecer de nos depararmos com uma unidade léxica que, como coloca Kasama (2015), denotativamente designa um povo, mas conotativamente reporta uma injúria, enquadrando-se, como explicitado anteriormente, em um tabu. Esses seriam etnônimos injuriosos, ou seja, unidades lexicais que se referem a um grupo étnico, racial ou social, com carga ofensiva.

É o que se vê em 'baiano', que parece ter o sentido pejorativo “motivado pelos hábitos e à simplicidade de modos desse povo" (KASAMA, 2015, p. 43). Há ainda a noção mais específica de etnofaulismo de Aedo e Farías (2009, p. 378) para "designar as maneiras pelas quais os membros de um grupo se referem a membros de outros grupos 
(exogrupos), especialmente quando os últimos são de origem étnica diferente". ${ }^{2}$ Neste estaria, por exemplo, o item 'cigano', relacionado a negociante esperto, vivo.

Ainda que extremamente ofensivo, no dicionário Michaelis, na acepção número 2 encontra-se a relação de cigano à pessoa que tem habilidade para negócios, com a marca de uso figurado, que pouco esclarece o leitor, mas que também não demonstra tom ofensivo no comentário semântico. O que também não se vê em 3, com a marca pejorativo (definido nesta obra como desagradável), que só descreve um vendedor ambulante, e 4, em que consta a mesma rubrica, que sinaliza ao consulente prudência ao adotar a unidade com a carga estigmatizada.

Figura 6 - cigano - Michaelis

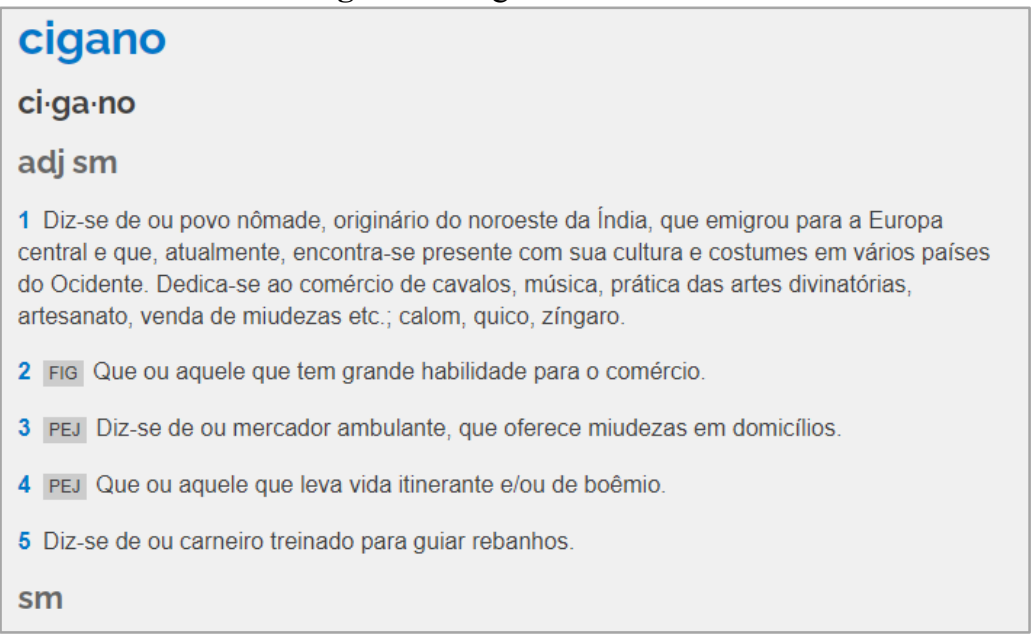

Fonte: dicionário Michaelis

Já no dicionário Aulete, na acepção número 3, encontra-se uma sinalização com a rubrica pejorativo (nele definido como algo que exprime desaprovação, depreciação), assim como no Priberam, na acepção 6.

Importante ressaltar que no verbete de pejorativo, Priberam é o único a apresentar, dentro de sua definição, como algo "a que se atribui significação desagradável, insultuosa, torpe ou obscena". Ou seja, comentário semântico que efetivamente sinaliza que o que está marcado com essa rubrica tem tom ofensivo.

\footnotetext{
2"designar las formas en que los miembros de un grupo se refieren a los miembros de otros grupos (exogrupos), especialmente cuando estos últimos son de un origen étnico diferente" (AEDO; FARÍAS, 2009, p. 378).
} 
Figura 7 - cigano -Aulete

cigano
sm.
1. Indivíduo dos ciganos, povo nômade, prov. originário da Índia, presente em vários países,
com cultura, ética e comportamento próprios, e conhecido esp. por se dedicar à música,
prática de artesanato, quiromancia, comércio de cavalos, etc.
2. Fig. Indivíduo boêmio, de vida incerta. [Por vezes, com uso pej.]
3. Pej. Negociante esperto, vivo
4. P.ext. Vendedor ambulante.
5. Gloss. Conjunto de dialetos pertencentes à família indo-europeia e falados por ciganos

Fonte: dicionário Aulete

Figura 8 - cigano - Priberam

ci·ga·no
(talvez do francês antigo cigain, francês tsigane ou tzigane)
adjetivo
1. Relativo a ou próprio dos ciganos, povo nômada, de origem
asiática, que se espalhou pelo mundo (ex.: canto cigano). =
zínGARO
2. [Linguistica] Relativo ao cigano enquanto sistema linguístico. =
ROMANI
adjetivo e substantivo masculino
3. Diz-se de ou indivíduo pertencente aos ciganos. = MANUCHE,
ZínGARO
4. [Informal] Que ou aquele que leva vida errante.
5. [Informal] Que ou aquele que tem arte e graça para captar as
vontades.
6. [Pejorativo] Que ou quem age com astúcia para enganar ou
burlar alguém. = BURLÃO, IMPOSTOR, TRAPACEIRO, VELHACO
7. [Pejorativo] Que ou aquele que é excessivamente agarrado ao
dinheiro. = AVARENTO, SOVINA
substantivo masculino
8. [Linguística] Língua indo-europeia dos ciganos do Oriente e da
Europa, constituída por um conjunto de dialetos. = ROMANI
9. [Ornitologia] Ave (Opisthocomus hoazin) arborícola semelhante
ao faisão, de cabeça pequena adornada com uma poupa eriçada
em forma de leque, asas largas e cauda comprida, encontrada no
norte da América do Sul. = CIGANA

Fonte: dicionário Priberam

Dentro do domínio dos etnônimos injuriosos, relembramos que nos anos 1950, segundo Rodríguez (2000), houve um movimento denominado como "A campanha dos dicionários", com a finalidade de retirar dos dicionários de língua portuguesa referências insultuosas a israelitas. A campanha envolveu grande parte da intelectualidade da época, projetando-se até para fora do Brasil.

Por meio de um requerimento do escritor, jornalista e advogado, Fernando Levisky, ao Ministro da Educação e Cultura da época, foi solicitada a retirada dos dicionários das definições ofensivas encontradas em verbetes. Por exemplo, o verbete 'judeu', que era definido como homem mau, negocista, avarento, trocista, etc (RODRÍGUEZ, 2000). 
O resultado foi parcialmente bem sucedido, pois durante seu andamento, os dicionários que foram publicados apareciam sem essas significações depreciativas. Dizemos que é um sucesso parcial, pois não acreditamos que uma obra de consulta deva tolher de seu consulente uma ou outra acepção, mas deve apresentá-la com as devidas ressalvas acerca de seu uso.

Um dos primeiros a fazer essa adequação foi o Dicionário Contemporâneo, de Caldas Aulete, em sua edição de 1958, segundo Rodríguez (2000), que hoje está disponível on-line.

Figura 9 - judeu - Aulete

\begin{tabular}{l}
\hline judeu \\
1. Hist. Pessoa da antiga tribo de Judá \\
2. Hist. Pessoa do antigo reino hebreu de Judá (Sul da Palestina) \\
3. Hist. Pessoa nascida ou que vivia na Judeia, antiga região da Palestina \\
4. Quem pratica o judaísmo: Os judeus confraternizaram -se com os cristãos no culto \\
ecumênico. \\
5. Bras. Cul. Variedade de bolo de milho \\
6. MG Cul. Virado de frango ao molho pardo e carne de porco \\
7. MG Refeicão noturna: CEIA
\end{tabular}

Fonte: Aulete

No Michaelis, ainda se mantém para 'judeu' a acepção objeto de crítica na metade no século XX, mas sinalizada em 6 com duas marcas, coloquial (definido na obra como informal, distenso) e pejorativo (desagradável).

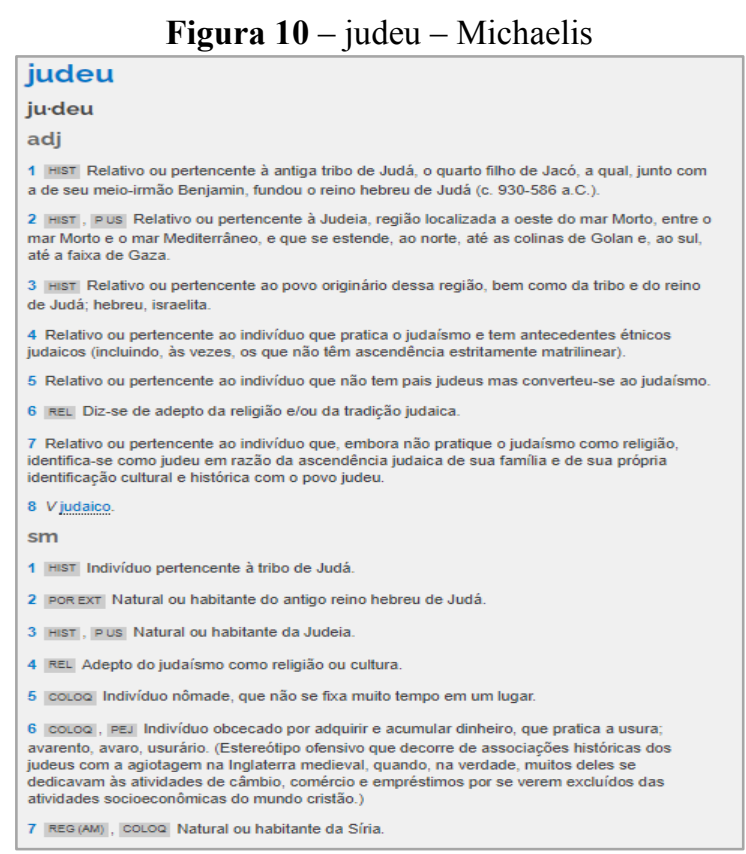

Fonte: dicionário Michaelis 
E no Priberam, na acepção 8, a primeira da classificação de substantivo consta a marca de uso informal, depreciativo:

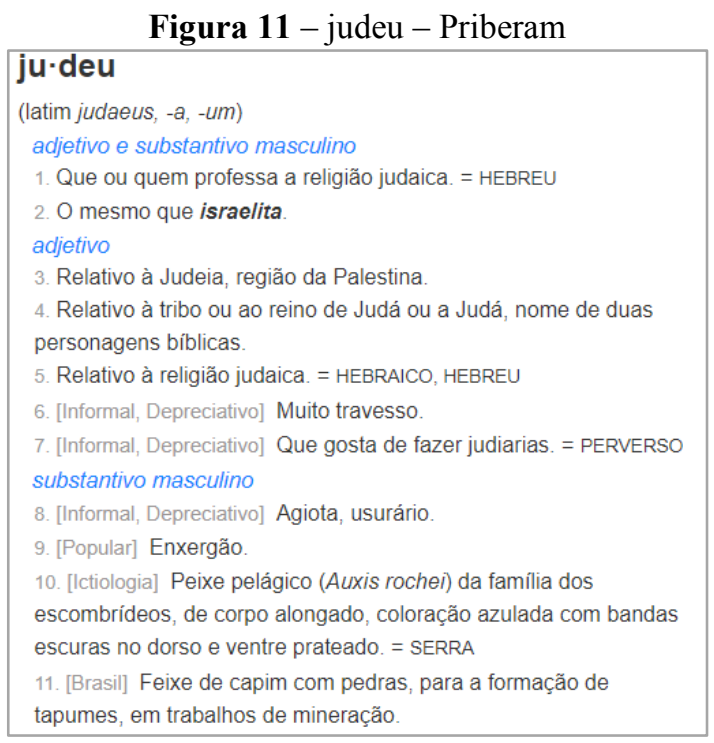

Fonte: dicionário Priberam

Estendendo o panorama de etnônimos, podemos pensar no verbete 'paulista', associado à pessoa teimosa.

No dicionário Michaelis, como substantivo não há essa carga semântica descrita, somente como adjetivo e com a rubrica figurado - e por essa razão a trouxemos aqui a fim de ilustração.

Figura 12 - paulista - Michaelis

paulista
pau-lis·ta
adj $m+f$
1 Relativo ou pertencente ao Estado de São Paulo; piratiningano.
2 FIG Que teima, insiste; que não desiste facilmente; birrento, obstinado, turrão.
3 REG (RS) Que é dado a desconfiar; cismado, desconfiado, ressabiado.
4 Diz-se de religioso pertencente à Ordem de São Paulo.
5 REG (BA) Diz-se de pessoa que amansa burros.
Sm+f
1 Natural ou habitante do Estado de São Paulo.
2 FIG Pessoa muito teimosa.
3 REG (RS) Aquele que não confia, que está sempre ressabiado.
4 Religioso pertencente à Ordem de São Paulo.
5 REG (BA) Amansador de burros.

Fonte: dicionário Michaelis 
Assim como no Priberam, em que só consta 'paulista' como sinônimo de pessoa birrenta como adjetivo, sem, contudo, nenhuma marcação para o uso insultuoso que pode ter.

Figura 13 - paulista - Priberam

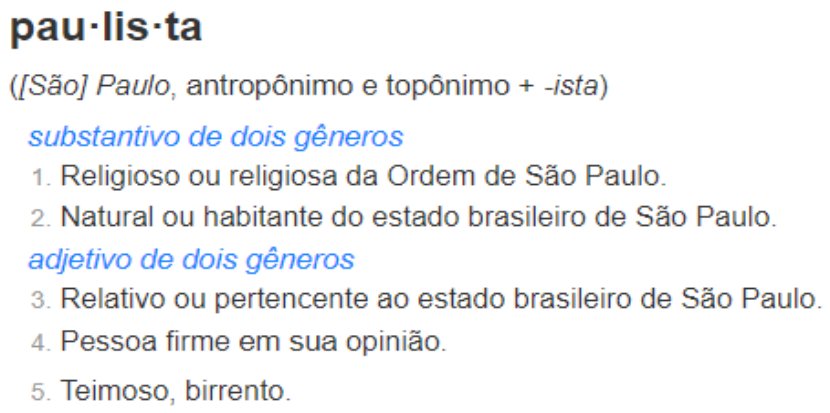

Fonte: dicionário Priberam

No Aulete, tem-se a marca de uso figurado, número 2, e, satisfatoriamente, dentro do comentário de 'paulista' como substantivo.

Figura 14 - paulista - Aulete

\begin{tabular}{|l|}
\hline paulista \\
\hline (pau.lis.ta) \\
s2g. \\
1. Pessoa nascida ou que vive no Estado de São Paulo \\
2. Fig. Pessoa teimosa, birrenta. \\
3. RS Pessoa muito desconfiada. \\
4. BAAmansador de burros. \\
5. Integrante da Ordem de São Paulo. \\
\hline
\end{tabular}

Fonte: dicionário Aulete

Pode-se ver, da leitura dos verbetes, o que diz Béjoint (2000, p. 131) sobre o fato de que "em dicionários de uso geral, muitas definições refletem as atitudes usuais da sociedade sobre todos os tipos de questões ideológicas, políticas ou morais. Isso vale não apenas para tabus e etnônimos, mas também para as palavras usadas na descrição de sistemas políticos, e para muitas outras que são difíceis de classificar". 3

As escatologias também são alvo de tabu. Conforme Orsi e Bueno $(2014$, p. 6):

\footnotetext{
3 “In general-purpose dictionaries, many definitions reflect the society's general attitudes on all sorts of 80 ideological, political, or moral issues. This is true not only for taboo words and of ethnonyms, but also of the words used in the description of political systems, and of many other that are difficult to classify" (BÉJOINT, 2000, p. 131).
} 
Itens escatológicos, como merda e mijo, também são tabuizados por representarem o significado de uma forma menos eufemística e mais representativa. Tais palavras são consideradas chulas e de baixo calão e os usuários desse léxico podem ser julgados como pessoas grosseiras. Como essas palavras representam algo que as pessoas ignoram, ou tentam ignorar, e que representam questões sobre o corpo, termos científicos são utilizados para eufemizar seus significados.

Por exemplo, no Michaelis, 'mijo', para referir urina, recebe a rubrica coloquial.

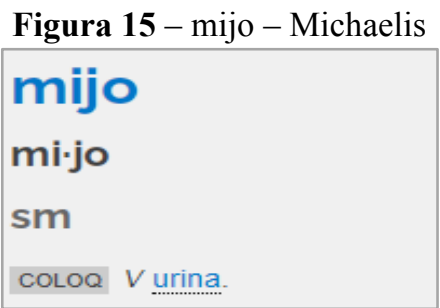

Fonte: dicionário Michaelis

Já no Aulete, a rubrica é popular.

Figura 16 - mijo - Aulete

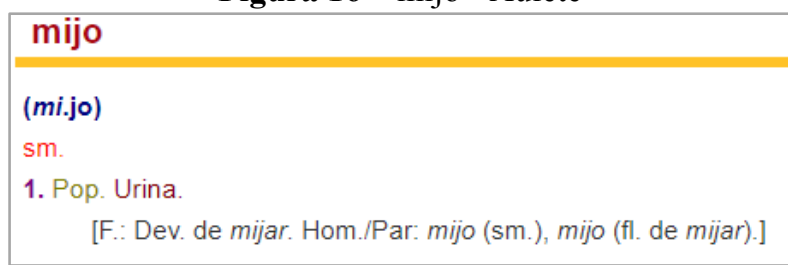

Fonte: dicionário Aulete

Somente Piberam é mais específico, ao classificar como tabuísmo (definido na obra como ofensivo, pejorativo e chulo, fazendo referência a órgãos genitais e suas funções sexuais, metabolismos e disfemismos extremamente grosseiros).

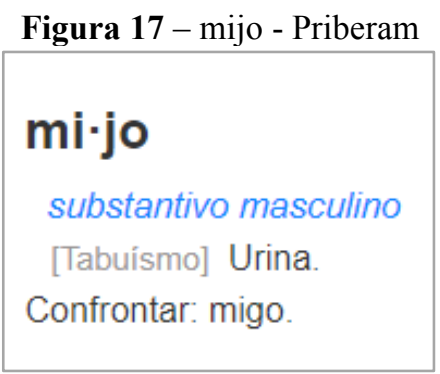

Fonte: dicionário Priberam 
Em relação ao ato sexual, buscamos o registro de 'trepada', substantivo que refere ao sexo como um ato de violação (NAGEM; AMARAL, 2005), envolvendo força, intensidade e pouco afeto.

No Michaelis, na acepção 3 vemos a ligação com a relação sexual marcada como vulgar.

Figura 18 - trepada - Michaelis

\begin{tabular}{|l|}
\hline trepada \\
tre-pa.da \\
sf \\
1 Terreno em aclive; ladeira, subida. \\
2 coloo Ato ou efeito de repreender ou censurar, admoestação, reprimenda. \\
3 vulo Relação sexual; foda, metida, pingolada. \\
\hline
\end{tabular}

Fonte: dicionário Michaelis

No Aulete, a rubrica que recebe no número 2 é tabu (definido na obra como algo sagrado, restrito, proibido).

Figura 19 - trepada - Aulete

\begin{tabular}{|l|}
\hline trepada \\
(tre.pa.da) \\
sf. \\
1. Ação ou resultado de trepar \\
2. Bras. Tabu. Ato sexual; CÓPULA \\
3. Caminho muito inclinado; LADEIRA; SUBIDA \\
4. Pop. Reprimenda, repreensão [Antôn.: elogio, louvor. ] \\
[F.: Fem.substv. de trepado]
\end{tabular}

Fonte: dicionário Aulete

No Priberam, na acepção número 5, recebe a marca de uso informal.

Figura 20 - trepada - Priberam

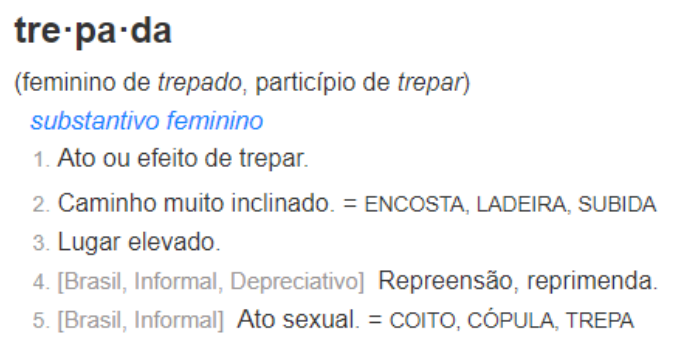

Fonte: dicionário Priberam 
Lembramos que outra metáfora também ligada ao ato sexual é sua associação a uma refeição - o ato de comer. Para Lévi-Strauss (1996, p. 122): “essas aproximações nada mais fazem do que ilustrar, em casos particulares, a analogia profunda que, em todo o mundo, o pensamento humano parece fazer entre o ato de copular e o de comer, a tal ponto que um grande número de línguas os denominam com a mesma palavra".

Ao buscarmos por 'comida', referente ao sexo, encontramos no Michaelis, não a relação ao ato sexual, mas sim a pessoa com quem se faz sexo e, com acréscimo aleatório do complemento 'às escondidas'. A marca de uso adotada é vulgar (definido por inúmeros sinônimos como 'popular, banal corriqueiro, baixo ou grosseiro).

Figura 21 - comida - Michaelis

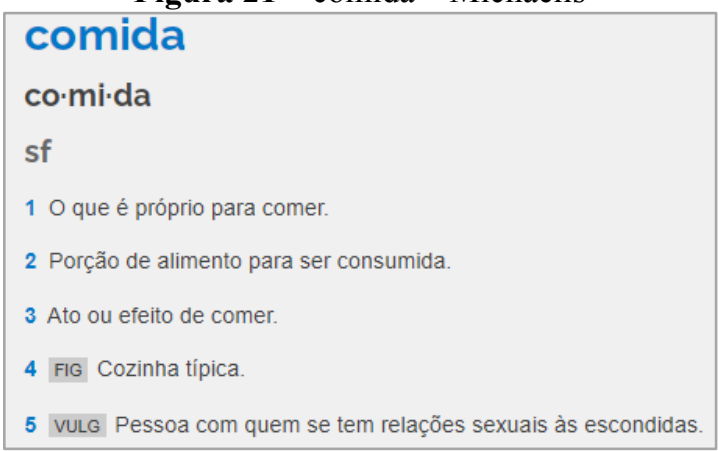

Fonte: dicionário Michaelis

Assim como no Michaelis, também no Aulete e no Priberam, 'comida' não se refere ao ato sexual, mas somente às pessoas nele envolvidas, como se pode ver abaixo, respectivamente.

No Aulete, a marca de uso para as acepções 4 e 5 é tabu e no Priberam, em 4, informal.

Figura 22 - comida - Aulete

Comida
(co.mi.aa)
sf.
1. O que é próprio para se comer; o que se come
2. Refeição, esp. almoço ou jantar: Afinal chegara a hora da comida.
3. Ato de comer.
4. Conjunto de pratos típicos ou característicos de um país, região etc.: A comida chinesa.
5. Tabu. Pessoa com quem se tem secretamente relações sexuais.
6. Tabu. Pessoa que se oferece ou se entrega (para relação sexual)

Fonte: dicionário Aulete 
Figura 23 - comida - Priberam

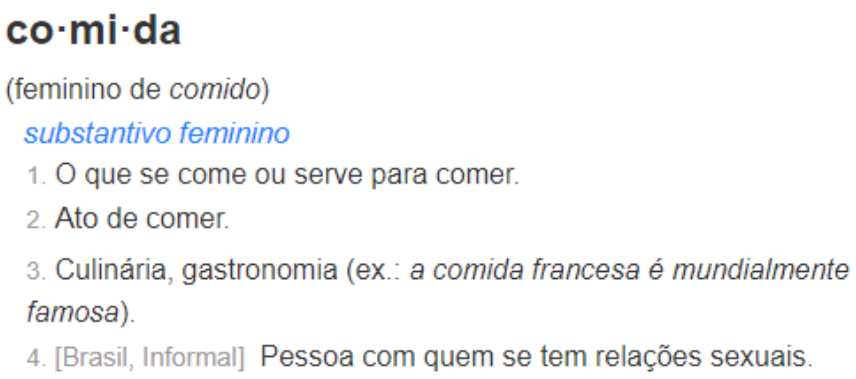

Fonte: dicionário Priberam

Percebemos que as ocorrências, marcações e as omissões nos comentários semânticos da microestrutura dos dicionários aqui consultados testemunham os tabus linguísticos de uma comunidade e a falta de ou pouca clareza no aviso ao consulente sobre as marcas de uso.

Ainda segundo Orsi e Bueno (2014, p. 405):

\begin{abstract}
O dicionário é um objeto que está intimamente ligado à cultura, nele estão conservadas as lexias em uso. Sendo, portanto, verdadeira fonte de riqueza no que diz respeito aos estudos da língua, pois contém nele a cultura lexical de um povo. Podemos estudar pelos dicionários, a história da língua e como algumas palavras são definidas, mostrando, dessa forma, a visão de mundo de um povo e os processos por que ela passou até chegar ao que é atualmente. Sendo as obras lexicográficas, então, ligadas à cultura, nelas podemos entrever como os costumes mudam e algumas práticas da sociedade se alteram ou até desaparecem.
\end{abstract}

Vemos, enfim, como diz Borba (2003, p. 320), que "a necessidade de rotulação vem da observação dos mais variados textos de língua escrita (...), não tanto quanto à recepção, mas quanto à viabilidade de avaliação das circunstâncias de uso, principalmente quando se trata de consulente estrangeiro". E por isso, segundo ele, a tarefa de registrar e apresentar marcas de uso é complicada e feita de forma irregular em nossos dicionários, recebendo pouca atenção de lexicógrafos.

Finalizamos defendendo que os dicionários deveriam enfatizar e dar mais atenção às marcas diaevaluativas. A análise delas permite-nos não apenas verificar o rigor metodológico (ou a ausência dele) nas obras quanto a sentidos injuriosos e ofensivos, como também a relevância ou irrelevância de alguns deles. O que se percebe com os verbetes apresentados é uma incongruência no momento de indicar essas marcas, sem uniformidade e justificativa. 


\section{Considerações finais}

Para findar as considerações feitas neste artigo, cabe-nos salientar que acreditamos que a decisão de incluir ou excluir unidades léxicas tabus em um dicionário depende dos objetivos com que a obra é elaborada.

Se o dicionário é concebido como uma obra descritiva, cremos que devam ser registradas todas as palavras que tenham uso frequente e generalizado, ainda que existam pudor e juízos sociais contrários ao seu emprego.

Ademais, a inclusão de itens que possam ter acepções depreciativas e chulismos em casos específicos como em dicionários escolares deveria ser repensada, pois inúmeras crianças e jovens acabam por repeti-los muitas vezes sem saber exatamente o que significam, impossibilitando a autonomia do consulente. Incluir unidades léxicas como as descritas e palavrões no dicionário poderia indicar seu grau de ofensa ao desvelar o tabu que as circunda.

O caráter normativo dessas marcas reside no fato de que rubricar uma acepção como tabu/tabuísmo, chulo, vulgar ou alguma outra, por exemplo, é uma informação extremamente importante para o consulente, pois este saberá que se trata de uma unidade lexical cujo uso é restrito ou é mais adequado a determinados contextos.

A Lexicografia necessita deixar claro os usos que descreve nos dicionários, o que se dá principalmente por meio da inclusão de marcas que devem ser melhor pensadas e reelaboradas, inclusive para que haja certa uniformidade entre os diversos dicionários.

Por fim, sobre a inserção desses itens tabuizados em dicionários, acreditamos, assim como Correia (2008), que a Lexicografia deixou de privilegiar a faceta prescritiva que a caracterizou durante séculos, para centrar os seus esforços numa tentativa de descrição o mais eficiente possível das unidades lexicais como efetivamente empregadas.

Somente assim o dicionário se firmará como suporte efetivo para a ampliação dos conhecimentos linguísticos e para a constituição individual como sujeitos.

\section{Referências}

AEDO, S.; FARÍAS, M. Etnofaulismos, coprolalia, representaciones y estrategias discriminatorias: el caso del discurso chileno antiperuano. Discurso \& Sociedad, vol. 3(3), p.372-396, 2009. 
AULETE, C. Aulete Digital. Dicionário contemporâneo da língua portuguesa: Dicionário Caldas Aulete, online. Lexikon Editora digital. Disponível em: http://www.aulete.com.br/. Acesso em 05 jul. 2020.

BÉJOINT, H. Modern Lexicography: an introduction. Oxford: Oxford University Press, 2000.

BORBA, F. S. Organização de dicionários: uma introdução à lexicografia. São Paulo: UNESP, 2003.

BUGUEÑO MIRANDA, F. V.; BORBA, L. C. (orgs.) Manual de (Meta)Lexicografia. Goiânia: Editora Espaço Acadêmico, 2019.

CORREIA, M. Lexicografia no início do século XXI - novas perspectivas, novos recursos e suas consequências. In: JÚNIOR, M. A. (coord.) Lexicon - Dicionário de Grego-Português/Actas de Colóquio. Lisboa: Centro de estudos Clássicos/FLUL, p. 73-85, 2008.

FAJARDO, A. Las marcas lexicográficas: concepto y aplicación práctica en la Lexicografía española. Revista de Lexicografía, v. 111, p. 31-57, 1996-1997

FRANKENBERG-GARCIA, A. The lexicography of Portuguese. In: HANK, P.; DE SCHYVER, G. M. (orgs.). International Handbook of Modern Lexis and Lexicography. Springer, Berlin, Heidelberg, p.1-10, 2017.

GUÉRIOS, M. Tabus Linguísticos. Curitiba: Editora “Organização Simões”, 1956.

HENRIQUES, C. C. Léxico e semântica. Rio de Janeiro: Elsevier, 2011.

KASAMA, D. Y. Etnofaulismos e os dicionários monolíngues brasileiros. São José do Rio Preto: 2015, 207f. Tese (Doutorado em Estudos Linguísticos) - IBILCE/UNESP.

LÉVI-STRAUSS, C. Antropologia estrutural. Tradução de Chaim Samuel Katz e Eginardo Pires. Rio de Janeiro: Tempo Brasileiro, 1996.

MICHAELIS. Dicionário Brasileiro da Língua Portuguesa. Editora: Melhoramentos Ltda. Disponível em: https://michaelis.uol.com.br/moderno-portugues/. Acesso em 05 jul. 2020.

MORALES, H. L. Sociolinguística del tabú. Disponível em: http://www.usal.es/gabinete/comunicacion/conferencia_humberto.pdf. Acesso em 05 nov. 2006.

NAGEM, R. L.; AMARAL, S. E. Analogias e metáforas na educação afetivo-sexual. Anais V ENPEC - Encontro Nacional de Pesquisa em Educação em Ciências. São Paulo: Edwaldo Lima da Silva e Sérgio Camargo, p. 1-12, 2005. 
ORSI, V. Tabu e preconceito linguístico. Revista Virtual de Estudos da Linguagem, v. 9, p. 334-348, 2011.

ORSI, V.; BUENO, M. S. Turpilóquio em português e italiano: reflexões sobre marcas de uso de itens tabus em dicionários. Domínios de Lingu@Gem, v. 8, p. 399-412, 2014.

PRIBERAM, Dicionário priberam da lingua portuguesa. Porto/Portugal: Priberam, 2008. Disponível em: https://www.dicionario.priberam.com. Acesso em 05 jul. 2020.

RODRÍGUEZ, A. M. Tabus lingüísticos do Português do Brasil. Anais III Congresso Nacional de Lingüística e Filologia. Rio de Janeiro: Cadernos CNLF. v. 5. p. 86-94, 2000 .

WELKER, H. A. Dicionários - Uma pequena introdução à Lexicografia. Brasília, DF: Thesaurus, 2004.

Recebido em: 15 de setembro de 2020 Aceito em: 29 de março de 2021 Publicado em maio de 2021 